www.nature.com/ejhg

\title{
Molecular and biochemical characterisation of a novel sulphatase gene: Arylsulfatase G (ARSG)
}

\author{
Paola Ferrante ${ }^{1}$, Silvia Messali ${ }^{1,3}$, Germana Meroni $^{1}$ and Andrea Ballabio ${ }^{*, 1,2}$ \\ ${ }^{1}$ Telethon Institute of Genetics and Medicine (TIGEM), Via P. Castellino 111, 80131 Naples, Italy; ${ }^{2}$ Medical \\ Genetics, II University of Naples, Italy
}

Molecular analysis has provided important insights into the biochemistry and genetics of the sulphatase family of enzymes. Through bioinformatic searches of the EST database, we have identified a novel gene consisting of 11 exons and encoding a 525 aa protein that shares a high degree of sequence similarity with all sulphatases and in particular with arylsulphatases, hence the tentative name Arylsulfatase G (ARSG). The highest homology is shared with Arylsulfatase A, a lysosomal sulphatase which is mutated in metachromatic leukodistrophy, particularly in the aminoterminal region. The $\mathbf{1 0}$ amino acids that form the catalytic site are strongly conserved. The murine homologue of Arylsulfatase G gene product shows $87 \%$ identity with the human protein. To test the function of this novel gene we transfected the full-length cDNA in Cos7 cells, and detected an Arylsulfatase G precursor protein of $62 \mathrm{kDa}$. After glycosylation the precursor is maturated in a $70 \mathrm{kDa}$ form, which localises to the endoplasmic reticulum. Northern blot analysis of Arylsulfatase G revealed a ubiquitous expression pattern. We tested the sulphatase activity towards two different artificial substrates 4-methylumbelliferyl (4-MU) sulphate and $p$-nitrocatechol sulphate, but no arylsulphatase activity was detectable. Further studies are needed to characterise the function of Arylsulfatase $G$, possibly revealing a novel metabolic pathway. European Journal of Human Genetics (2002) 10, 813-818. doi:10.1038/sj.ejhg.5200887

Keywords: sulphatases; lysosomal storage disorders; multiple sulphatase deficiency

Sulphatases are members of a highly conserved gene family and share extensive sequence homology and a high degree of structural similarity. ${ }^{1,2}$ Sulphated glycosaminoglycans, glycolipids, glycoproteins and hydroxysteroids are hydrolysed by sulphatases, each of which has exquisite specificity towards its individual substrate in vivo. ${ }^{3,4}$ A subset of sulphatases, each with very different natural substrates, is active in vitro against a common set of small aromatic substrates, hence the name arylsulphatases. This functional correlation reflects a high degree of predicted amino acid sequence similarity along the entire length of the enzymes. This amino acid sequence conservation

\footnotetext{
*Correspondence: A Ballabio; Fax: +39-081-5609877;

E-mail: ballabio@tigem.it

${ }^{3}$ Current address: Istituto FIRC di Oncologia Molecolare (IFOM), Via Serio 21, 20134 Milan, Italy

Received 24 April 2002; revised 1 August 2002; accepted 2 August 2002
}

strongly suggests that the sulphatases are members of an evolutionarily conserved gene family sharing a common ancestor, which has undergone duplication events in several species. ${ }^{1,5}$ A more recent duplication has generated a cluster of sulphatase genes located on the distal short arm of the human X chromosome, in Xp22.3. ${ }^{6}$ Twelve human sulphatases have been identified and, on the basis of their subcellular localisation, they can be divided into two main categories: those acting at acidic $\mathrm{pH}$ sharing a lysosomal localisation, and those with a neutral $\mathrm{pH}$ optimum found in the endoplasmic reticulum and Golgi apparatus. $^{2}$ Most of these sulphatases have been identified by linking a clinical condition to a deficient function of one of these enzymes. ${ }^{7-9}$ Additional evidence that all sulphatases are functionally related comes from the study of a rare and intriguing genetic disease named multiple sulphatase deficiency (MSD) in which all known sulpha- 
tases are deficient. ${ }^{2}$ A major breakthrough in the understanding of the function of sulphatases has recently emerged from the observation that sulphatases undergo a common and unique co- or post-translational modification. This occurs in the endoplasmic reticulum and involves the oxidation of a conserved cysteine residue which is required for catalytic activity and is defective in MSD. ${ }^{10}$ All these data underline the importance of the sulphatase family and suggest that the identification of additional sulphatase genes creates novel opportunities to study human metabolism and disease mechanisms.

\section{Materials and methods}

Plasmids and constructs

ARSG expression vectors were obtained by cloning both the full-length and the coding sequence of ARSG CDNA into EcoRI-digested pcDL and EcoRI/Sal-digested pmt 21 vectors. ${ }^{11}$ ARSG (Ala) and ARSG (Pro) (see below) were both cloned in the two different vectors.

\section{Cos7 transfection and protein extract}

Cos7 cells were grown in Dulbecco's modified Eagle's medium (DMEM) supplemented with 10\% FCS, $100 \mathrm{~g}$ penicillin/ml, and $100 \mathrm{~g}$ streptomycin $/ \mathrm{ml}$, at $37^{\circ} \mathrm{C}$ in $5 \% \mathrm{CO}_{2}$ atmosphere. Ten micrograms of wild-type ARSG cDNA expression vector constructs were introduced into Cos7 cells, by electroporation using a BioRad Gene Pulser apparatus, and were seeded in 75$\mathrm{cm}^{2}$ flasks. The cells were harvested $24-72 \mathrm{~h}$ after transfection and were resuspended in extraction buffer $(150 \mathrm{~mm}$ $\mathrm{NaCl} ; 100$ mM Tris-HCl, pH 7.5; and 1\% Triton X-100) and cell lysates were clarified by centrifugation at $13000 \mathrm{rpm}$ to remove cell debris. The supernatant was mixed with SDSPAGE sample buffer, boiled, and loaded on the gel.

\section{Production of polyclonal antibody}

The region of amino acids 389-525 of ARSG was fused to the six-histidine tag bacterial expression vector $\mathrm{pQE}$ (Qiagen) and was produced in DH5 $\alpha$ cells, after induction with isopropyl- $\beta$-D-thiogalactoside (IPTG). The His-tagged protein was purified on a NiNTA agarose column (Qiagen) and was used to immunise rabbits. ARSG antiserum was precipitated with ammonium sulphate and the antibody was purified on a protein A-Sepharose column.

\section{Immunoblot}

Ten micrograms of soluble cellular protein was boiled for 5 min in sample buffer, electrophoresed through $10 \%$ SDS-PAGE, and electroblotted onto PVDF membrane (Amersham). The membrane was treated with 5\% dry milk in Tris-buffer saline with the addition of Tween 20 (TTBS (20 mM Tris- $\mathrm{HCl}, \mathrm{pH} 7 ; 50 \mathrm{~mm} \mathrm{NaCl}$; and $0.1 \%$ Tween 20)) to inhibit nonspecific binding. Anti-ARSG antibody was used at a 1:700 dilution in TTBS. Visualisation of antibody binding was performed with a secondary anti-rabbit IgG antibody conjugated with peroxidase.

\section{Immunofluorescence}

Immunofluorescence was performed on paraformaldehyde (PFA)-fixed transfected Cos7 cells. Cells were permeabilised with $0.2 \%$ Triton $\mathrm{X}-100$, blocked with porcine serum, and incubated with anti-ARSG antibody $(1: 700)$. Staining was obtained after incubation with secondary fluorescein isothiocyanate (FITC)- or tetramethylrhodamine isothiocyanate (TRITC)-conjugated isotype-specific antibody. Specific ER staining was obtained even by double staining with a commercially available anti-ER polyclonal antibody, ERAB (K-20) (Santa Cruz Inc). This antibody recognise a peptide mapping near the carboxy terminus of ERAB (endoplasmic reticulum amyloid beta-peptide-binding protein.)

\section{Endoglycosidase $\mathrm{H}$ and $\mathrm{F}$ treatment}

For glycosylation analysis, protein samples derived from transfected Cos7 cells were digested overnight with endoglycosidase $\mathrm{H}$ and $\mathrm{N}$-glycosidase F (Boerhinger Mannheim) in an appropriate buffer (50 mM phosphate buffer, $\mathrm{pH} 7.4$; 50 mм EDTA; 1\% NP40; $0.1 \%$ SDS; $1 \% \beta$-mercaptoethanol; $4 \mu \mathrm{g}$ of aprotinin per $\mathrm{ml} ; 2 \mu \mathrm{g}$ of leupeptin per $\mathrm{ml} ; 2 \mu \mathrm{g}$ of pepstatin per $\mathrm{ml}$ ) and were analysed by SDS-PAGE.

\section{Enzyme assay}

4-MU sulphate assay Cos7 cells were transfected with $10 \mu \mathrm{g}$ of either ARSG (Ala) or ARSG (Pro) cDNA constructs by electroporation and harvested by trypsinisation $72 \mathrm{~h}$ after transfection for enzyme assay. Cells were resuspended in $0.1 \mathrm{M}$ Tris- $\mathrm{HCl}$ (pH 7.5), 1\% Triton X-100, and $150 \mathrm{~mm}$ $\mathrm{NaCl}$. The incubation mixture was prepared with different $\mathrm{pH}$ buffer, from $\mathrm{pH} 4$ to 9 . The enzymatic assay was run at $37^{\circ} \mathrm{C}$ for $2 \mathrm{~h}$, the reaction was stopped adding $1 \mathrm{ml}$ of glycine-carbonate buffer ( $\mathrm{pH}$ 10.7) and fluorescence was determined on Hoefer TKO 100 fluorometer.

P-nitrocatechol sulphate assay Cos7 cells were transfected with $10 \mu \mathrm{g}$ of ARSG cDNA constructs by electroporation and harvested by trypsinisation $72 \mathrm{~h}$ after transfection for enzyme assay. Cells were resuspended in $0.1 \mathrm{M}$ Tris- $\mathrm{HCl}$ (pH 7.5), 1\% Triton X-100, and $150 \mathrm{~mm} \mathrm{NaCl}$. The incubation mixture was prepared with two different $\mathrm{pH}$ buffer, $\mathrm{pH} 4.9$ and 7.5. The enzymatic assay was run at $37^{\circ} \mathrm{C}$ for $2 \mathrm{~h}$, the reaction was stopped adding $700 \mu \mathrm{l}$ of $\mathrm{NaOH}(0.64 \mathrm{~N})$ and absorbance was determined at $515 \mathrm{~nm}$ on spectrophotometer.

\section{mRNA analysis}

Northern blots containing human RNAs from several tissues were purchased from Clontech and hybridised with a cDNA fragment of $885 \mathrm{bp}$ as a probe, using the conditions recommended by the manufacturer (Clontech). Washing conditions were $2 \times \mathrm{SSC}, 0.05 \%$ SDS at $58^{\circ} \mathrm{C}$ (Wash Solution I) and $0.1 \times \mathrm{SSC}, 0.1 \% \mathrm{SDS}$ at room temperature (Wash Solution II). RT-PCR experiments were performed with oligonucleotide primers from ARSG that amplify a $360 \mathrm{bp}$ product on samples from different murine tissues. PCR 
was carried out for 40 cycles. Annealing temperature was $60^{\circ} \mathrm{C}$ for ARSG primers.

\section{Results}

Identification of the ARSG gene

Bioinformatic searches of the EST and $\mathrm{nr}$ (non-redundant) databases identified a novel cDNA sequence that shares a high degree of homology with all sulphatases and in particular with arylsulphatases, hence the name of Arylsulfatase $\mathrm{G}$ (ARSG). This gene encodes a 525 amino-acid protein that shows the highest level of homology (37\% identity and $50 \%$ similarity) with Arylsulfatase A (Figure 1). Sequence alignment between this novel sulphatase with ARSA and ARSB revealed a high degree of amino-acid similarity along the entire length of the protein, particularly in the aminoterminal region. ${ }^{12,13}$ Moreover, the 10 residues that form the catalytic site of the protein are strongly conserved (Figure 1). ARSG cDNA (KIAA 1001) was generated by the large transcript identification project of the Kazusa Institute, Japan. The availability of mapped ESTs and of genomic sequences corresponding to the $A R S G$ transcripts allowed us to map this gene to $17 \mathrm{q} 23-\mathrm{q} 24$ and to define the intron-exon boundaries of the 11 exons that compose the gene (Table 1). The gene spans the genomic region from 72287512 to 72383112 (95600 bp). Comparison among the sequence of the KIAA 1001 clone with the available database sequences revealed a nucleotide change. The 501 codon GCA (Ala) in the genomic and EST sequences

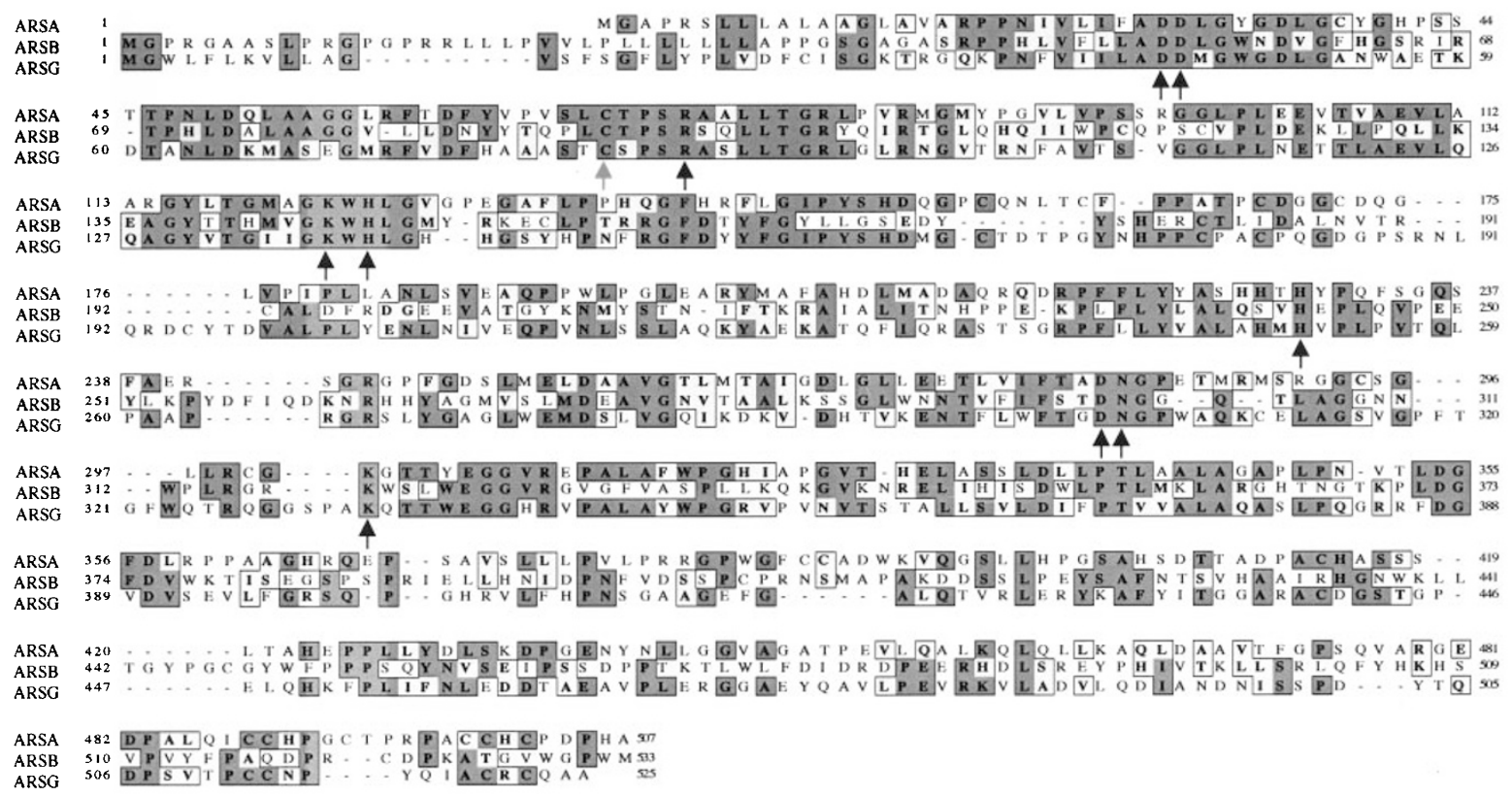

Figure 1 Multiple alignment of human arylsulphatases (A, B, G). Dark grey boxing indicates residues that are identical in at least two out of the three proteins; light grey indicates residues that are conserved in at least two out of the three proteins. Amino acids that are conserved in the catalytic pocket of all sulphatases are indicated with black arrows. The grey arrow indicates the conserved cysteine, contained in the consensus signature that undergoes conversion to 2-amino-3-oxopropionic acid in all eukaryotic sulphatases.

Table 1 Exon-intron boundaries of ARSG gene

\begin{tabular}{|c|c|c|c|c|c|c|}
\hline \multirow{2}{*}{$\frac{\text { Exon }}{1}$} & \multirow{2}{*}{$\frac{\text { Size }(b p)}{218}$} & \multirow{2}{*}{$\frac{c D N A \text { position }}{457-674}$} & \multicolumn{2}{|c|}{ 5' splice site } & \multicolumn{2}{|c|}{ 3' splice site } \\
\hline & & & GGGAATGAG & gtgagtctt & tccctgcag & GTT TGT GGA \\
\hline 2 & 188 & $675-862$ & GGATAATAG & ḡ̄aactctg & tttctacag & GCA AAT GGC \\
\hline 3 & 48 & $863-910$ & ACTTCCGTG & gtaagaatt & ctattccag & GTT TTG ATT \\
\hline 4 & 112 & $911-1022$ & ACCATCAAG & gtaatgctg & tccacacag & GAA CCT TCA \\
\hline 5 & 138 & $1023-1160$ & GCGTGCAAG & gtgaggagt & ctgtttcag & CAC CAG CGG \\
\hline 6 & 197 & $1161-1357$ & GGTTTACAG & gtaaagtag & ggtttctag & GAG ACA ATG \\
\hline 7 & 81 & $1358-1438$ & CTCGTCAAG & gtaagggc & ctcdtcacag & GGG GAA GTC \\
\hline 8 & 109 & $1439-1547$ & CTTGTTAAG & gtatgagac & tttccgcas & CGT GCT GGA \\
\hline 9 & 121 & $1548-1668$ & GGGCACAGG & ḡ̄tagtgga & ctttctca $\underline{a g}$ & GTG CTG TTC \\
\hline 10 & 91 & $1669-1759$ & ACATTACCG & gtgagtgag & cctctctag & GTG GAG CCA \\
\hline 11 & 275 & $1760-2034$ & & & & \\
\hline
\end{tabular}


(BG994996-BG744786-BE740712-AV654375-BM708401) is substituted by CCA (Pro) in the KIAA1001 clone. To test if this mutation affects the localisation and/or the activity of the protein we mutagenised the KIAA 1001 clone. All the experiments described below have been performed with both the original (ARSG Ala) and the mutated (ARSG Pro) clones and no different results were obtained. Moreover, through protein-protein blast (blastp) searches, we have identified the ARSG murine orthologue that shows $87 \%$ of identity with the human protein. In agreement with the human genomic and EST sequences, the mouse ARSG presents an alanine in the position corrisponding to the human 501 residue.

\section{Characterisation of ARSG in transfected Cos7 cells}

We raised polyclonal antibody against the $\mathrm{C}$-terminal portion of the ARSG protein. The region of amino acids 389-525 was fused to a six-histidine tag bacterial expression vector and was then expressed in $\mathrm{DH} 5 \alpha$ cells and used to immunise rabbits. The antiserum was raised against a region where the sulphatases share the lowest degree of homology to prevent crossreaction with other members of the family. This antiserum (anti-ARSG Q57) was used in Western blotting analysis of protein extracts from Cos7 cells transfected with tagged and non-tagged vectors, and a band of $70 \mathrm{kDa}$ was identified (Figure 2). The amino-acid sequence of the predicted ARSG protein reveals the presence of four putative $\mathrm{N}$-glycosylation sites (asparagine residues 117, 215, 356, and 497) (Figure 2). Treatment with endoglycosidase $\mathrm{H}$ and $\mathrm{F}$ reduced the size of the $70 \mathrm{kDa}$ polypeptide by $8 \mathrm{kDa}$, suggesting that the increase in molecular size observed in the maturation of $A R S G$ is due to $\mathrm{N}$-glycosylation (Figure 3). Assuming that the average mass of an oligosaccharide is $2 \mathrm{kDa}$, all four $\mathrm{N}$ glycosylation sites maybe utilised, accounting for the $8 \mathrm{kDa}$ shift observed in SDS-PAGE.

\section{Intracellular localisation of ARSG}

Several sulphatases identified thus far are lysosomal proteins. Non lysosomal sulphatases include STS, which has a microsomal localisation, ARSD and ARSF which are located in the endoplasmic reticulum and ARSE which is located in the Golgi apparatus. ${ }^{1,2}$ The subcellular localisation of ARSG (Ala) in transfected Cos7 cells was established by immunofluorescence techniques using a myc-tagged construct, recognised by anti-myc antibody. The use of a specific anti$A R S G$ antibody confirmed this result and revealed a typical reticular distribution of the protein. The reticular localisation was also confirmed by double staining with a specific anti-ER antibody, ERAB (K-20) (Figure 4). The same results were obtained with the ARSG (Pro) (data not shown).

\section{Enzymatic analysis}

To test a putative arylsulphatase activity of the protein, ARSG (Ala) and ARSG (Pro) cDNA constructs were transiently transfected into Cos7 cells by electroporation. After

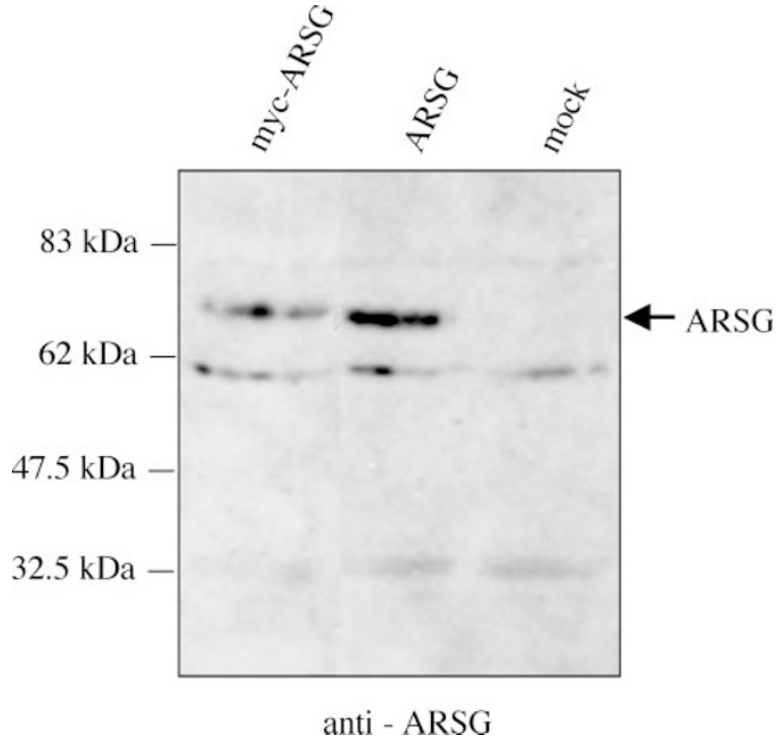

Figure 2 Western blotting analysis: soluble cellular proteins from cells extracts were analysed by SDS - PAGE followed by immunoblot with anti-ARSC antibody. A band of $70 \mathrm{kDa}$ was detectable in Cos7 cells transfected with myc-ARSG (lane 1) and with ARSG (lane 2).

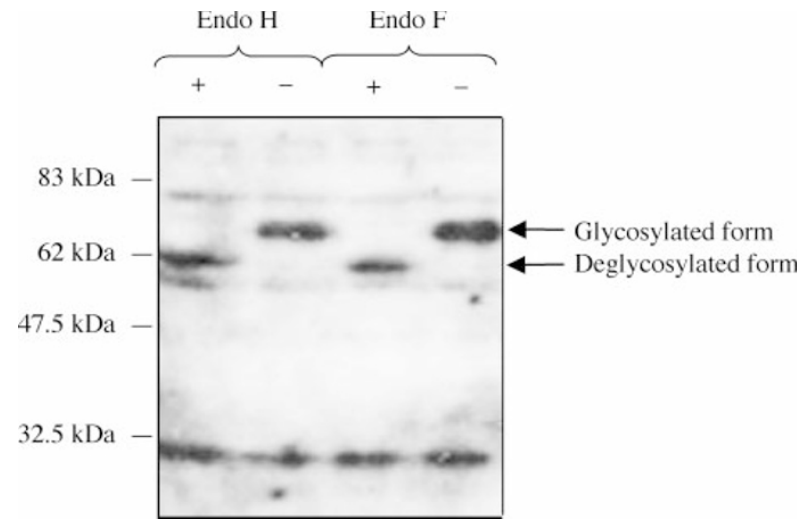

Figure 3 Glycosylation of the ARSG gene product. Cos7 cells were transfected with myc-ARSG, cell extracts were subjected to endoglycosidase $\mathrm{H}$ and $\mathrm{N}$-glycosidase $\mathrm{F}$ treatment and were analysed by SDS-PAGE, together with the untreated extracts. After endoglycosidase treatment, the $70 \mathrm{kDa}$ polypeptide was converted into the $62 \mathrm{kDa}$ form.

$72 \mathrm{~h}$ the total cell extracts were assayed at different $\mathrm{pH}$ ( $\mathrm{pH}$ range from $\mathrm{pH} 4$ to 9) for their ability to hydrolyse the sulphate group from 4-methylumbelliferyl (4-MU) sulphate. As control we used Cos7 cells transfected with ARSE cDNA construct. ${ }^{11}$ No arylsulphatase activity was detectable in the extracts obtained from cells transfected with the constructs (Figure 6). These results indicate that in these conditions the ARSG gene product is unable to hydrolyse the $4 \mathrm{MU}$ sulphate. The enzymatic assays were 
A
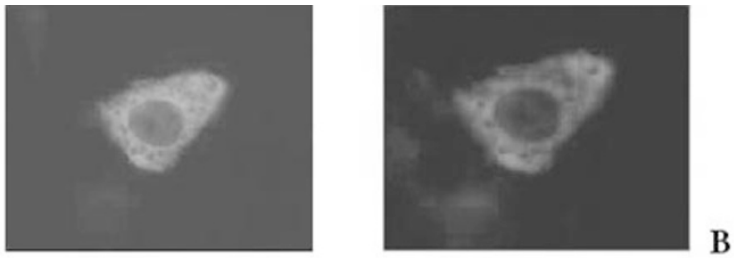

$\mathrm{C}$
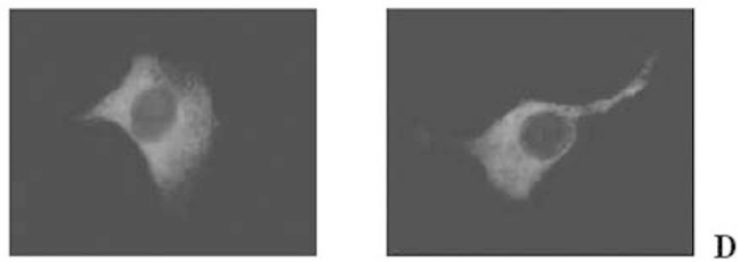

E

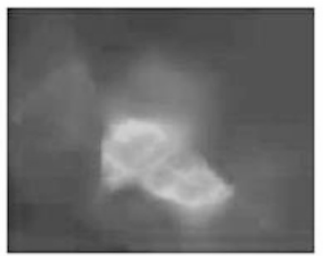

Figure 4 Localisation of ARSG in transfected cells. Cos 7 cells were transfected with myc-ARSG (A, B) and with ARSG (C-F). (A, B) Staining using anti-Myc antibody, followed by FITC antimouse antibody, and anti-ARSG antiserum, followed by TRITC anti-rabbit antibody, respectively. (C, D) Staining using purified anti-ARSG antibody, followed by FITC anti-rabbit antibody. (E, F) Double staining immunofluorescence using anti-ARSG antibody, followed by FITC anti-rabbit antibody, and anti-ER antibody, followed by TRITC anti-goat antibody respectively.

also performed using the $p$-nitrocatechol sulphate, another artificial substrate. We obtained the same result with no activity toward this substrate (data not shown).

\section{ARSG expression pattern}

Northern blot analysis revealed a low level and ubiquitous expression pattern of human ARSG mRNA. Pancreas, kidney and brain showed slightly higher levels of expression (data not shown). Detection of murine ARSG mRNA by RT-PCR allowed us to investigate the expression pattern of this gene in mouse. Reverse-transcribed RNA samples from different tissues were amplified by PCR using oligonucleotide primers generated from the murine cDNA sequence. A ubiquitous expression pattern was observed similarly to what we detected in human tissues (Figure 5). In addition to RTPCR and Northern blot analysis, we performed RNA in situ hybridisation experiments. Analysis of sagittal and coronal sections of E12.5 and E14.5 mouse embryos revealed a low level and ubiquitous expression pattern confirming the Northern blotting and RT-PCR results (data not shown).

\section{Discussion}

In most instances the identification of the sulphatase genes resulted from the biochemical characterisation of a known

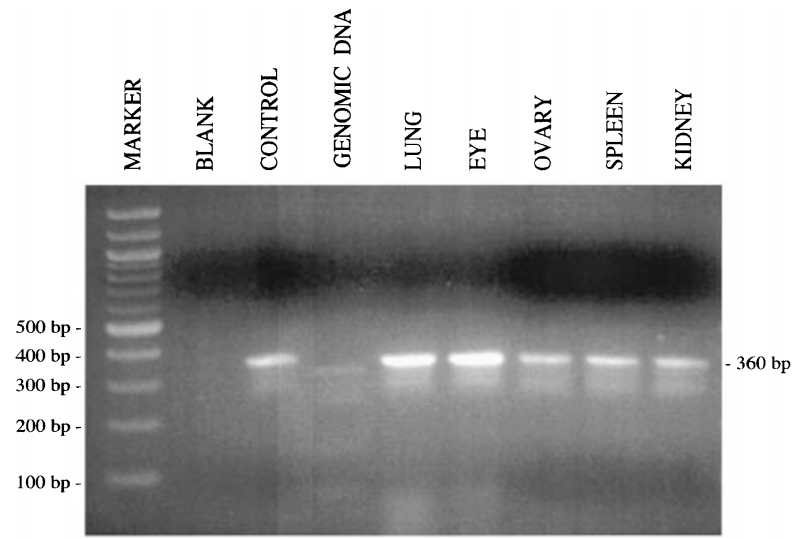

Figure $5 \mathrm{RT}-\mathrm{PCR}$ analysis of murine ARSG gene. Oligonucleotide primers from murine ARSG CDNA were used for the amplification of reverse-transcribed total RNA from different mouse tissues. ARSG primers amplify a 360 bp product.

human disease. ${ }^{7-9}$ More recently, we have identified a cluster of sulphatase genes by positional cloning ${ }^{11,14}$. Here we describe the identification of a novel sulphatase gene, ARSG, by a bioinformatic approach using the DBWatcher tool. This allows a periodic and systematic screening of the expressed sequence and genomic databases using sequences from genes or proteins of interest as queries. This strategy does not rely on the knowledge of the gene product or of its substrate specificity and enzymatic properties. In addition no genetic disease related to an enzymatic defect links to the region where the gene maps, consequently it is difficult to predict the function of the protein. ARSG protein shares a high degree of homology with all sulphatases and in particular with arylsulphatases. Sequence alignment of the putative protein product of this new gene with other sulphatases, in particular with ARSA and ARSB, has revealed a high degree of amino acid similarity. The three sequences are very similar along the entire length of the protein, particularly in the amino-terminal region, where the consensus sulphatase signature is located (Figure 1). The active site of sulphatases has been characterised and shown to display unique features. ${ }^{12,13}$ A modified cysteine residue and a metal ion are located at the base of a substrate-binding pocket. ${ }^{10}$ The amino-acid residues conserved throughout the sulphatase family play a role in stabilising the calcium ion and the sulphate ester in the active site. ${ }^{15}$ To try to understand the physiological role of this new gene we started a biochemical characterisation of the ARSG protein. We detected two molecular forms of $A R S G$, a 62 and $70 \mathrm{kDa}$ protein, in cell extracts after transfection. The $62 \mathrm{kDa}$ polypeptide is converted into a $70 \mathrm{kDa}$, which is likely to represent the mature enzyme, with an increase in size due to N-glycosylation. The amino acid sequence contains four potential $\mathrm{N}$ glycosylation sites (asparagine residues 117, 215, 356, and 497). Assuming that the average mass of an oligosaccharide is $2 \mathrm{kDa}$, all four $\mathrm{N}$-glycosylation sites are potentially utilised, accounting for the $8 \mathrm{kDa}$ shift observed in SDS-PAGE. ARSA 
Enzyme Assay

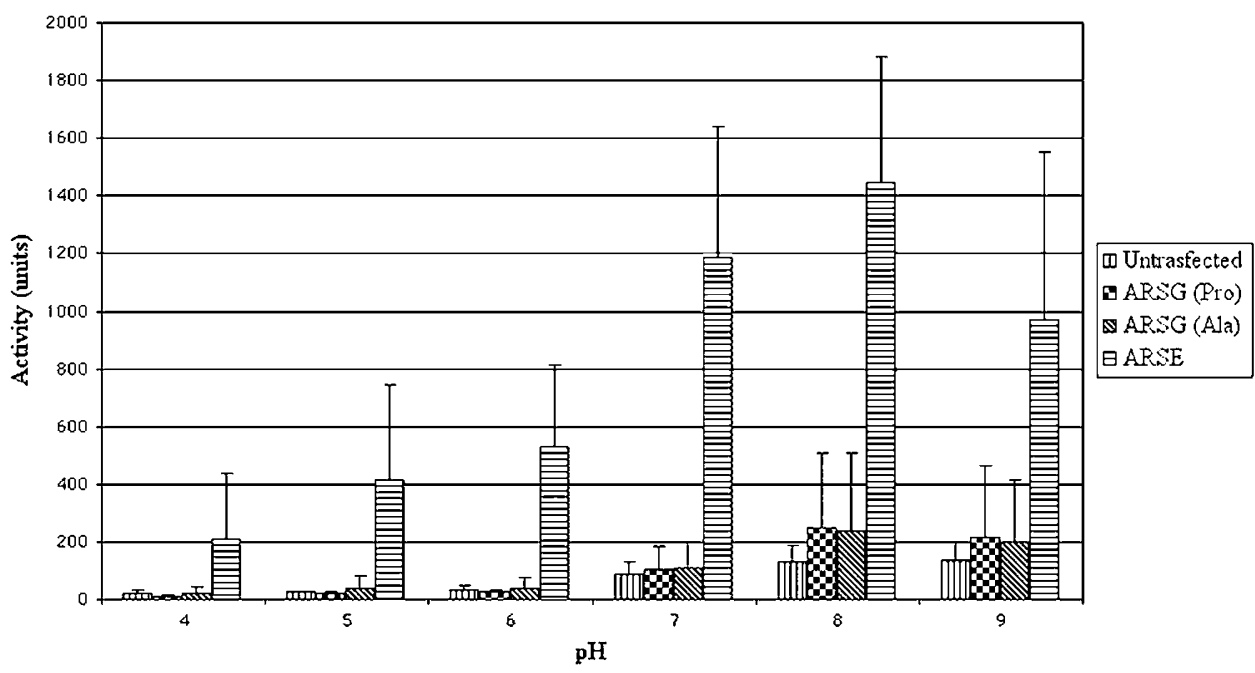

Figure 6 Biochemical study of ARSG expressed in COS7 cells. Evaluation of ARSG arylsulphatase activity on 4-MUS at different pH values.

and ARSB are able to hydrolyse sulphated artificial substrates containing a phenolic ring (arylsulphatase activity), such as p-nitrocatechol sulphate or 4-methylumbelliferyl sulphate (4-MU sulphate) and are lysosomal in their subcellular localisation. ${ }^{1}$ Surprisingly, ARSG does not show activity towards these substrates under the specified conditions and localises in the endoplasmic reticulum. Similarly to $A R S G$, a previous identified sulphatase, $A R S D$, is highly homologous to other arylsulphatases but does not show arylsulphatase activity. ${ }^{14}$ In conclusion, the identification of this additional sulphatase gene creates novel opportunities to study human metabolic pathways. Further studies are needed to characterise the biological role of ARSG. To this purpose we are planning to generate mice deficient for this enzyme by a gene targeting approach. This strategy will allow us to study, in the animal model, the pathological consequences of the enzyme deficiency and to clarify the metabolic role of this new sulphatase.

\section{Acknowledgements}

This work was supported by the Italian Telethon Foundation and by the European Community (grant no. QLRT-1999-00793 to A Ballabio).

\section{References}

1 Parenti G, Meroni G, Ballabio A: The sulfatase gene family. Curr Opin Genet Dev 1997; 7: 386-391.

2 Hopwood JJ, Ballabio A (ed): Multiple sulfatase deficiency and the nature of the sulfatase family; in Scriver CR, Beaudet AL (eds): The metabolic and molecular basis of inherited disease. New York: McGraw-Hill, 2001; 3, pp 3725-3732.

3 Bergner E, Shapiro L: Metabolism of 3H-dehydroepiandrosterone sulphate by subjects with steroid sulphatase deficiency. J Inherit Metab Dis 1988; 11: 403-415.
4 Roy AB (ed): Enzymological aspects of steroids conjugation; in Bernstein S, Solomon S (eds): Chemical and Biological Aspects of Steroid Conjugation,. New York: McGraw-Hill, 1970, p 74.

5 Peters C, Schmidt B, Rommerskirch W et al: Phylogenetic conservation of arylsulfatases. cDNA cloning and expression of human arylsulfatase B. J Biol Chem 1990; 265: 3374-3381.

6 Meroni G, Franco B, Archidiacono N et al: Characterisation of a cluster of sulfatase genes on Xp22.3 suggests gene duplications in an ancestral pseudoautosomal region. Hum Mol Genet 1996; 5: $423-431$

7 von Figura K, Gieselmann V, Jaeken J (ed): Metachromatic leukodystrophy; in Scriver CR, Beaudet $\mathrm{AL}$ (eds): The methabolic and molecular basis of inherited disease. New York: McGraw-Hill, 2001; 3, pp 3695-3724.

8 Ballabio A, Shapiro LJ (ed): Steroid sulfatase deficiency and Xlinked ichthyosis; in Scriver CR, Beaudet AL (eds): The methabolic and molecular basis of inherited disease. New York: McGraw-Hill, 2001; 3, pp 4241-4262.

9 Neufeld EF, Muenzer J (ed): The mucopolysaccharidoses; in Scriver CR, Beaudet AL (eds): The methabolic and molecular basis of inherited disease. New York: McGraw-Hill, 2001; 3, pp 3421-3452.

10 Schmidt B, Selmer T, Ingendoh A, von Figura K: A novel amino acid modification in sulfatases that is defective in multiple sulfatase deficiency. Cell 1995; 82: 271-278.

11 Franco B, Meroni G, Parenti G et al: A cluster of sulfatase genes on Xp22.3: mutations in chondrodysplasia punctata (CDPX) and implications for warfarin embryopathy. Cell 1995; 81: 15-25.

12 Bond CS, Clements PR, Ashby SJ et al: Structure of a human lysosomal sulfatase. Structure 1997; 5: 277-289.

13 Lukatela G, Krauss N, Theis $\mathrm{K}$ et al: Crystal structure of human arylsulfatase A: the aldehyde function and the metal ion at the active site suggest a novel mechanism for sulfate ester hydrolysis. Biochemistry 1998; 37: 3654-3664.

14 Puca AA, Zollo M, Repetto $M$ et al: Identification by shotgun sequencing, genomic organization, and functional analysis of a fourth arylsulfatase gene (ARSF) from the Xp22.3 region. Genomics 1997; 42: 192-199.

15 Selmer T, Hallmann A, Schmidt B, Sumper M, von Figura K: The evolutionary conservation of a novel protein modification, the conversion of cysteine to serine-semialdehyde in arylsulfatase from Volvox carteri. Eur J Biochem 1996; 238: 341-345. 